\title{
Tuning the modulus of nanostructured ionomer films of core-shell nanoparticles based on poly(n-butyl acrylate)
}

DOI:

10.1039/C6SM01563H

\section{Document Version}

Accepted author manuscript

Link to publication record in Manchester Research Explorer

\section{Citation for published version (APA):}

Musa, M. S., Milani, A., Peter, S., Simpson, G., Lovell, P., Eaves, E., Hodson, N., \& Saunders, B. (2016). Tuning the modulus of nanostructured ionomer films of core-shell nanoparticles based on poly(n-butyl acrylate). Soft Matter, 12(39), 8112-8123. https://doi.org/10.1039/C6SM01563H

\section{Published in:}

Soft Matter

\section{Citing this paper}

Please note that where the full-text provided on Manchester Research Explorer is the Author Accepted Manuscript or Proof version this may differ from the final Published version. If citing, it is advised that you check and use the publisher's definitive version.

\section{General rights}

Copyright and moral rights for the publications made accessible in the Research Explorer are retained by the authors and/or other copyright owners and it is a condition of accessing publications that users recognise and abide by the legal requirements associated with these rights.

\section{Takedown policy}

If you believe that this document breaches copyright please refer to the University of Manchester's Takedown Procedures [http://man.ac.uk/04Y6Bo] or contact uml.scholarlycommunications@manchester.ac.uk providing relevant details, so we can investigate your claim.

\section{OPEN ACCESS}




\title{
Tuning the modulus of nanostructured ionomer films of core-shell nanoparticles based on $\operatorname{poly}(n$-butyl acrylate)
}

\author{
Muhamad S. Musa ${ }^{a}$, Amir H. Milani $^{a}$, Peter Shaw ${ }^{c}$, Gareth Simpson ${ }^{c}$, Peter A. Lovell ${ }^{a}$, \\ Elizabeth Eaves $^{a}$, Nigel Hodson ${ }^{b}$ and Brian R. Saunders ${ }^{a}$ * \\ ${ }^{a}$ Polymer Science and Technology Group, MSS Tower, School of Materials, The University \\ of Manchester, Manchester, M13 9PL, U.K. \\ ${ }^{b}$ BioAFM Facility, Stopford Building, The University of Manchester, Oxford Road, \\ Manchester, M13 9PT, UK. \\ ${ }^{c}$ Synthomer (UK) Ltd, Temple Fields, Harlow, Essex, CM20 2BH, U.K.
}

\begin{abstract}
In this study we investigate the structure-mechanical property relationships for nanostructured ionomer films containing ionically crosslinked core-shell polymer nanoparticles based on poly( $n$-butyl acrylate) (PBA). Whilst nanostructured ionomer films of core-shell nanoparticles have been previously shown to have good ductility [Soft Matter, 10, $4725,2014]$, the modulus values were modest. Here, we used BA as the primary monomer to construct core-shell nanoparticles that provided films containing nanostructured polymers with much higher glass transition temperature $\left(T_{g}\right)$ values. The core-shell nanoparticles were synthesised using BA, acrylonitrile (AN), methacrylic acid (MAA) and 1, 4-butanediol diacrylate (BDDA). Nanostructured ionomer films were prepared by casting aqueous coreshell nanoparticle dispersions in which the shell - $\mathrm{COOH}$ groups were neutralised with $\mathrm{KOH}$ and $\mathrm{ZnO}$. The film mechanical properties were studied using dynamic mechanical analysis and tensile stress-strain measurements. The use of BA-based nanoparticles increased the $T_{g}$ values to close to room temperature which caused a strong dependence of the film mechanical properties on the AN content and extent of neutralisation of the $-\mathrm{COOH}$ groups. The Young's modulus values for the films ranged from 1.0 to $86.0 \mathrm{MPa}$. The latter is the highest modulus reported for cast films of nanostructured ionomer films prepared from coreshell nanoparticles. The films had good ductility with strain-at-break values of at least $200 \%$. The mechanical properties of the films were successfully modelled using the isostrain model. From comparison with an earlier butadiene-based system this study demonstrates that the
\end{abstract}


nature of the primary monomer used to construct the nanoparticles can profoundly change the film mechanical properties. The aqueous nanoparticle dispersion approach used here provides a simple and versatile method to prepare high modulus elastomer films with tuneable mechanical properties.

\section{INTRODUCTION}

Core-shell nanoparticles continue to attract considerable interest ${ }^{1-3}$ because of the ability to tune their properties through independent control of the materials comprising the core and shell structures. Core-shell nanoparticles can also exhibit interesting stimuli-responsive physical and chemical properties ${ }^{3-5}$. Much of this research is driven by their property changes in response to external stimuli, such as temperature ${ }^{6}, \mathrm{pH}^{5}$ and ionic strength ${ }^{7}$. However, elastomeric films constructed using core-shell nanoparticles containing $\mathrm{COOH}$ groups have received less attention. Our previous work introduced ductile nanostructured elastomeric films prepared by casting films from aqueous dispersions of low glass transition temperature $\left(T_{g}\right)$ core-shell nanoparticles in the presence of $\mathrm{ZnO}^{8,9}$. The latter was used to neutralise the surface $-\mathrm{COOH}$ groups and introduced ionic inter-particle crosslinking. Those core-shell nanoparticles were prepared using 1,3-butadiene (Bd), acrylonitrile (AN) and methacrylic acid (MAA). The proportions of AN and MAA and extents of neutralisation were shown to affect the modulus values ${ }^{8,9}$. Whilst those nanostructured ionomer films had good ductility, their modulus values were low. Also, the use of $\mathrm{Bd}$, which has a boiling point of $-5{ }^{\circ} \mathrm{C}$, restricted the versatility for nanoparticle preparation because a high pressure reactor was required $^{8}$. In this study, we sought to overcome both the versatility and modulus deficiencies by investigating core-shell nanoparticles prepared using $n$-butyl acrylate (BA) in place of Bd. BA has a much higher boiling point $\left(145^{\circ} \mathrm{C}\right)$ which enabled conventional (non-pressurised) emulsion polymerisation equipment to be used for nanoparticle preparation. Furthermore, poly $\left(n\right.$-butylacrylate) (PBA) has a $T_{g}$ of $-49{ }^{\circ} \mathrm{C}^{10}$ which is about $20{ }^{\circ} \mathrm{C}$ higher than the $T_{g}$ for $\mathrm{PBd}^{8}$. We hypothesised that increasing the $T_{g}$ of the nanoparticle phases would provide higher modulus nanostructured films with built-in modulus tuneability afforded by the AN and MAA groups. Accordingly, an aim of the study was to investigate the role of $T_{g}$ on the mechanical properties of nanostructured ionomer films.

Ionomers are polymers which contain a low concentration (less than $\sim 15$ mol. \%) of ionic groups ${ }^{11-13}$ e.g., carboxylates. These groups can strongly enhance the modulus due to the presence of physical crosslinks involving ionic aggregates. In a low dielectric constant 
polymer matrix containing ionic groups multiplets and ionic clusters can form ${ }^{12-14}$. Multiplets contain a small number of closely spaced ion pairs; meanwhile, ionic clusters contain many multiplets $^{12}$. Whilst conventional ionomers are now well understood ${ }^{13}$, there have been relatively few studies involving core-shell nanoparticle ionomer films ${ }^{15}$, which are the subject of the present work. Kim et al. ${ }^{16}$ studied ionomer films prepared using poly(butyl methacrylate) dispersions and showed that neutralisation converted the acid-rich phase at the interparticle boundary into an ionomer phase. Gurney et al. ${ }^{17}$ recently studied the effect of $\mathrm{pH}$ on the mechanical properties of PBA-poly(acrylic acid) diblock copolymers. Bose et al. studied self-healing for PBA ionomers cast from solution and proposed that reversible ionic crosslinks were formed ${ }^{18}$. Ionomers prepared using polymer chains with precisely sequenced ionic groups have also been studied ${ }^{19}$. The overwhelming majority of ionomer films studied to date have been prepared by casting films of linear polymers from organic solvent-based solutions ${ }^{20}$ or using compounding ${ }^{21}$ or compression molding ${ }^{15,22}$. However, there has been relatively little work reported for nanostructured ionomeric films prepared from aqueous dispersions ${ }^{8,9}$, which is an approach with obvious environmental benefits.

Previously, we explored the structure-property relationships for low modulus Bd-based coreshell nanostructured ionomer films and probed methods for controlling their mechanical properties ${ }^{9,23,24}$. For those soft films it was shown that inclusion of AN was an effective method for tuning the modulus of the films ${ }^{8}$. AN is known to increase the surface hardness ${ }^{25}$, modulus $^{26}$ and tensile strength ${ }^{27}$ and thermal stability ${ }^{28,29}$ of copolymers due to the strong polarity of nitrile groups ${ }^{28}$ and strong molecular interactions ${ }^{30}$. However, all of our previous nanostructured ionomer films used $\mathrm{Bd}$ as the main structural monomer ${ }^{9,23,24}$. For the coreshell systems, Bd compromised more than $~ 70 \mathrm{wt} . \%$ of the nanoparticles and the Young;s modulus values were less than $12 \mathrm{MPa}^{8,9,24}$. Here, we replaced $\mathrm{Bd}$ with $\mathrm{BA}$ in order to explore the role of the $T_{g}$ of the main structural component in determining the mechanical properties of the nanoparticle films. PBA-based core-shell nanoparticles have been the subject of a number of studies ${ }^{15,31-33}$. However, they have not been studied as nanostructured ionomer films cast from aqueous dispersions to the best of our knowledge.

The approaches used to synthesise the core-shell nanoparticles and prepare the nanostructured ionomeric films studied in this work are depicted in Scheme 1a and b, respectively. The core-shell nanoparticles were prepared by seeded emulsion polymerisation. Two types of core-shell nanoparticle systems were synthesised: a high core volume fraction 
system (lower branch of Scheme 1a) and a low core volume fraction system (upper branch of Scheme 1a). The starting point for both systems was the PBA seed (Cs100(0)) nanoparticles. (The code used for all the nanoparticles is shown in Scheme 1b.) The seed was grown further for the high core volume fraction systems (Stage 2) to produce larger PBA core (C100(0)) nanoparticles. Higher $T_{g}$ copolymer shells of PBA-AN-MAA-BDDA (BDDA is 1,4butanediol diacrylate) were then grown on the core C100(0) nanoparticles (Stage 3, lower branch of Scheme 1a). By contrast, the low core volume fraction system used copolymer shell growth directly from the seed Cs100(0) nanoparticles (upper branch of Scheme 1a). For both core-shell nanoparticle systems the nanostructured films were formed by casting $\mathrm{pH}$-adjusted mixed aqueous dispersions containing the nanoparticles and $\mathrm{ZnO}$ (Scheme 1b) which resulted in the $-\mathrm{COOH}$ groups being neutralised by both $\mathrm{K}^{+}$and $\mathrm{Zn}^{2+}$.

In this study, we investigated the effect of both PBA-based core-shell nanoparticle composition and neutralisation on the mechanical properties of new PBA-based nanostructured ionomer films. The characterisation data for the core-shell nanoparticles are first discussed and the effect of neutralisation on nanoparticles are then studied to establish conditions for film formation. We then investigated the effect of nanoparticle composition on the film mechanical properties. For these films the AN content was found to be crucial in positioning the film $T_{\mathrm{g}}$ either close to or above room temperature and this was shown to have a major effect on the mechanical properties as well as the ionomer contribution to the film modulus. We also show that the isostrain model can be used to describe the mechanical properties of the nanostructured films and compare the results for the BA-based systems with a Bd-based system from previous work. This study provides a simple route to high modulus nanostructured films with good ductility using procedures that are water-based and versatile.

\section{EXPERIMENTAL}

\section{Materials}

Unless otherwise stated all materials were purchased from Aldrich. Aerosol MA-80 (Cytec, $\geq$ $80 \%)$, potassium persulphate (KPS, $\geq 99 \%)$, BDDA $(\geq 99 \%)$ and $t$-dodecylmercaptan $(\geq$ 99\%) were used as received. Inhibitor was removed from the BA (Merck, $\geq 99 \%)$ and AN ( $\geq$ 99\%) by washing with dilute aqueous $\mathrm{NaOH}$ solution and water. MAA (99\%) was purified by passing the monomer through a column filled with aluminium oxide (alumina) gel. $\mathrm{ZnO}$ (55 wt.\%) was obtained from Aquaspersions Ltd., UK and had an average particle size of $600 \mathrm{~nm}$. Ultrahigh purity deionised water was used in all experiments. 


\section{Synthesis of core-shell nanoparticle dispersions}

The core-shell nanoparticle dispersions were synthesised using seed-feed or seed/core-feed emulsion polymerisation (See Scheme 1a). The code used for the nanoparticles is $\mathrm{C} v(w)-x(y)$; where $v, w, x$ and $y$ are the nominal total core vol.\%, wt.\% BDDA in the core, wt.\% AN in the shell and wt.\% BDDA in the shell, respectively. Accordingly, C55(0)-30(1) nanoparticles contained a (crosslinker-free) core volume fraction of 55 vol.\% and the shell contained 30 wt.\% AN and 1 wt.\% of BDDA. PBA seed dispersions (Cs100(0), Stage 1) were synthesised by emulsion polymerisation. For most of the systems a second growth stage of PBA was used to produced larger core nanoparticles $(\mathrm{C} 100(0)$, Stage 2) using the $\mathrm{Cs} 100(0)$ nanoparticles as the seed.

The following provides an example for the preparation of C55(0)-30(1). All polymerisations were carried out under an Ar atmosphere at $75^{\circ} \mathrm{C}$. Water $(300 \mathrm{~g})$ was added to a $2 \mathrm{~L}$ reaction vessel. Then, a surfactant solution of Aerosol MA-80 (14 $\mathrm{g}$ in $76 \mathrm{~g}$ of deionised water) was added. After 5 min of stirring, BA (54.0 g, $0.42 \mathrm{~mol})$ was added which was then followed by KPS addition ( $1.37 \mathrm{~g}$ in $54 \mathrm{~g}$ of deionised water). After polymerisation for $60 \mathrm{~min}$ the seed (Cs100(0)) nanoparticles were obtained. To prepare the core $(\mathrm{C} 100(0))$ nanoparticles, a mixture of deionised water (171.5 g), Aerosol MA-80 (2.97 g), $t$-dodecylmercaptan (0.085 g) and BA (237.5 g, $2.13 \mathrm{~mol}$ ) were slowly added at $5.5 \mathrm{~g} \mathrm{~min}^{-1}$ and the particle growth continued. Then a mixture of Aerosol MA-80 (2.97 g), $t$-dodecylmercaptan (0.085 g) and shell co-monomer feed solution (237.5 g) was added to the C100(0) core dispersion at a feed rate of $3.2 \mathrm{~g} \mathrm{~min}^{-1}$. The feed solution contained BA (64 wt.\%), AN (30 wt.\%), MAA (5 wt.\%) and BDDA (1 wt. \%). After $4 \mathrm{~h}$, the latex was filtered through a sieve $(28 \mu \mathrm{m})$. Samples were taken during the reaction and the $\%$ conversion determined gravimetrically and the z-average diameter $\left(d_{\mathrm{z}}\right)$ measured using DLS. Other systems were prepared using the same approach as described above by preserving the MAA content used for the shell and varying the AN content as required. In the case of C19(0)-55(1) the shell stage used the seed (Cs100(0)). Table 1 gives a summary of the system compositions prepared for this study.

To investigate nanoparticle growth during the emulsion polymerisation processes the number-density of nanoparticles $\left(N_{p}\right)$ was calculated from the measured $d_{z}$ values and the mass of monomer converted $(m)$ per unit volume to polymer using:

$$
N_{p}=\frac{6 m}{\pi \rho d_{z}^{3}}
$$


where $\rho$ is the density of the copolymer $(1.0 \mathrm{~g} / \mathrm{ml})$. Theoretical $d_{z}$ values for the nanoparticles during growth were calculated using the values for $m$ and the assumption that all of the core nanoparticles were converted to core-shell nanoparticles.

\section{Nanostructured ionomeric film preparation}

The method for $\mathrm{pH}$ adjustment, $\mathrm{ZnO}$ neutralisation and film preparation was similar to that described earlier ${ }^{34}$. The nominal extent of neutralisation is the mol. $\%$ of total cation added $\left(\mathrm{K}^{+}\right.$ and $\mathrm{Zn}^{2+}$ ) with respect to the nominal mol.\% of MAA present within the nanoparticles. Three extents of neutralisation were investigated; 0, 50 and 100\%, which are termed $0 \mathrm{n}, 50 \mathrm{n}$ and 100n, respectively. The films prepared without $\mathrm{pH}$ adjustment (0n) were cast in the as-made state. The initial $\mathrm{pH}$ of those dispersions was 3.0. The 50n nanoparticle films were cast from dispersions that were adjusted to $\mathrm{pH} 8.0$ using $\mathrm{KOH}$ solution. The 100n nanoparticle films were cast at $\mathrm{pH} 8.0$ in the presence of $\mathrm{ZnO}$. The latter films were neutralised by $\mathrm{K}^{+}(50 \%)$ and $\mathrm{Zn}^{2+}(50 \%)$.

The following is an example for the preparation of C55(0)-30(1) 100n films. An aqueous dispersion of C55(0)-30(1) ( $30 \mathrm{wt} . \%$ ) was stirred at $200 \mathrm{rpm}$ for $15 \mathrm{~min}$ at room temperature and adjusted to $\mathrm{pH} 8.0$ with aqueous $\mathrm{KOH}$ solution $(0.9 \mathrm{M})$. Sufficient $\mathrm{ZnO}$ dispersion to achieve 100n was added and the dispersion was equilibrated overnight. A clean glass plate (100 mm width x $125 \mathrm{~mm}$ length x $5 \mathrm{~mm}$ depth) was used for dispersion casting. The nanoparticle dispersion ( $20 \mathrm{~g}$ ) was poured onto the plate. The cast films were allowed to dry for three days in air circulating constant temperature oven at $25{ }^{\circ} \mathrm{C}$ in a humidity controlled environment (50\% RH). The dried nanostructured films had a thickness of $450 \pm 50 \mu \mathrm{m}$.

\section{Characterisation techniques}

Titration measurements were performed using a Mettler DL titrator in the presence of aqueous $\mathrm{NaCl}$ solution $(0.1 \mathrm{M})$. The $d_{z}$ values were measured by dynamic light scattering (DLS) using a Zetasizer NanoZS (Malvern Instruments Ltd., UK). TEM observations were conducted using a Philips CM 20 operated at an accelerating voltage of $200 \mathrm{kV}$. The nanoparticles were negatively stained using phosphotungstic acid solution (2 wt. \%). At least 100 particles were counted to determine the number-average particle diameter $\left(d_{T E M}\right)$. AFM measurements were conducted using an Asylum Research MFP-3D operated in tapping mode to map the surface topography of the film under ambient conditions. Imaging was performed at a scan speed of $1 \mathrm{~Hz}$ using Olympus high aspect ratio etched silicon probes (OTESPA) (Bruker AXS S.A.S, France) with a nominal spring constant of $42 \mathrm{~N} / \mathrm{m}$. A $1 \mathrm{~cm}$ x $1 \mathrm{~cm}$ 
section of film was cut and mounted on glass slide and placed inside the instrument. Measurements were made on film surfaces using a tip oscillation frequency of $307-346 \mathrm{kHz}$; height and phase images were captured at a scan size of $2 \times 2 \mu \mathrm{m}$ (sampled at $512 \times 512$ pixels). Dynamic mechanical analysis (DMA) data were measured using a TA-Q800 instrument using the film tension mode geometry and a frequency of $1 \mathrm{~Hz}$. Tensile tests were performed using a Hounsfield H10KS-0079 tensile testing instrument. Samples were prepared as dumbbell shapes. The lengths and widths were $75 \mathrm{~mm} 4.0 \mathrm{~mm}$, respectively. The extension rate was $500 \mathrm{~mm} \mathrm{~min}^{-1}$. The measurements were performed at $25{ }^{\circ} \mathrm{C}$ and $50 \%$ relative humidity.

\section{RESULTS AND DISCUSSION}

\section{Core-shell nanoparticle synthesis and characterisation}

For this study six core-shell nanoparticle dispersions were prepared using emulsion polymerisation (Table 1). Two sizes of core nanoparticles were prepared (Scheme 1a). The seed (Cs100(0)) had a $d_{z}$ of $45 \mathrm{~nm}$ and was used directly to prepare the C19(0)-30(1) nanoparticles. The latter had the lowest core volume fraction of all the core-shell systems studied and a $d_{z}$ of $76 \mathrm{~nm}$ (Table 1). To prepare the nanoparticles with higher core volume fractions $(\mathrm{C} 55(0)-x(1), x=20-30)$, the seed was grown further to produce core $\mathrm{C} 100(0)$ nanoparticles (Stage 2) which had a $d_{z}$ of $79 \mathrm{~nm}$.

Particle growth during nanoparticle synthesis was studied using DLS and data for C19(0)30(1) and C55(0)-30(1) are shown in Fig. 1a and b, respectively. (Particle growth data for C55(0)- $x(1)(x=20,23$ and 28) are shown in Fig. S1a - c.) The transition from the initial seed Cs100(0) to the core-shell nanoparticles is indicated for C19(0)-30(1) in Fig. 1a using the numbers 1 and 3. For C55(0)-30(1) the Cs100(0) core was prepared during Stage 2. For all of the systems the values for $N_{p}$ remained approximately constant during the various growth stages and there was reasonable agreement between the calculated and theoretical diameters (Fig. 1 and Fig. S1). These data indicate that secondary nucleation was not significant for the dispersions and support the view that core-shell nanoparticles were successfully prepared. The $d_{z}$ values for the final core-shell nanoparticles were in the range of 76 to $97 \mathrm{~nm}$ (Table 1).

TEM images for C19(0)-30(1) and C55(0)-30(1) nanoparticles are shown in Fig. 1c and d, respectively. (TEM images for C55(0)- $x(1)(x=20,23$ and 28) are shown in Fig. S1d - f, respectively.) The C19(0)-30(1) nanoparticles (Fig. 1c) were smaller than the C55(0)-30(1) nanoparticles (Fig. 1d) due to the use of the smaller seed Cs100(0) nanoparticles used for the 
former. (Fig. 1e and f show TEM images for seed Cs100(0) and core C100(0) nanoparticles). There was little, if any, evidence of secondary nucleation from the TEM images for the coreshell nanoparticles. The $d_{T E M}$ values (Table 1) for the core-shell nanoparticles (63 - $93 \mathrm{~nm}$ ) were reasonably close to the respective $d_{z}$ values, which shows that the dispersions were colloidally stable. The shell thicknesses $(\delta)$ were calculated using the $d_{z}$ values for the coreshell nanoparticles and those for the respective core nanoparticles $(\mathrm{Cs} 100(0)$ or $\mathrm{C}(100(0))$ and appear in Table 1. The $\delta$ values were largest for C19(0)-30(1) (15.5 nm) and were smallest for the C55(0)-x(1) systems (6.0 - $9.0 \mathrm{~nm})$, as expected.

Potentiometric titration was used to determine the MAA contents and apparent $\mathrm{p} K_{a}$ values for the nanoparticles (Fig. S2). The MAA contents were in the range $2.1-3.8$ wt.\% and were close to the values expected from the nominal compositions (Table 1, last column). These results seem to show that all of the $-\mathrm{COOH}$ groups were accessible, and not buried within the interior of the nanoparticles. However, it is not possible to be completely certain that all of the $-\mathrm{COOH}$ groups were accessible. The $\mathrm{p} K_{a}$ values for the core-shell nanoparticles were in the range of 6.7 to 7.4. The latter values were much lower than the $\mathrm{p} K_{a}$ values reported earlier for related PBd-AN-MAA core-shell nanoparticles ${ }^{8}$, which had $\mathrm{p} K_{a}$ values $\geq 9.1$. These results show that the nature of the primary structural monomer has a major effect on the $\mathrm{p} K_{a}$ for this family of core-shell nanoparticles, which is a new observation.

The procedure used to prepare nanostructured films followed our earlier approach ${ }^{8}$ and required the $\mathrm{pH}$ of concentrated dispersions to be increased to 8.0 (See Experimental section). The dispersions contained added $\mathrm{ZnO}$ particles which provided a source of soluble $\mathrm{Zn}^{2+}$. Films were subsequently cast onto flat glass molds (Scheme 1b). The use of $\mathrm{pH} 8.0$ ensured a balance between the supply of soluble $\mathrm{Zn}^{2+}$ (which decreases with increasing $\mathrm{pH}^{35}$ ) and dispersion stability ${ }^{8}$. Whilst this procedure worked very well for our previously reported Bdbased nanoparticle dispersions ${ }^{8}$ (which had $\mathrm{p} K_{a}$ values $\geq 9.1$ ) our initial attempts using crosslinker-free BA-based nanoparticles (i.e., C55(0)-30(0)) resulted in poor quality cast films. Variable-pH DLS measurements showed that the $d_{z}$ values for these nanoparticles increased with increasing $\mathrm{pH}$ (Fig. 2a). The nanoparticles swelled as the $\mathrm{pH}$ approached the $\mathrm{p} K_{a}$, which was 7.0 (Table 1). A tube inversion study (Fig. 2b) showed that concentrated C55(0)-30(0) dispersions formed a physical gel at $\mathrm{pH}$ 8.0. The latter prevented smooth films being prepared using our dispersion casting method.

In an effort to restrict shell swelling we prepared nanoparticles containing $1.0 \mathrm{wt} . \%$ BDDA, 
e.g., C55(0)-30(1). Not only did the (C55(0)-30(1) nanoparticles not show pH-triggered swelling as evidenced by variable pH DLS data (Fig. 2a), a tube inversion study for concentrated C55(0)-30(1) dispersions at pH 3.0 and 8.0 (Fig. 2b) showed that the C55(0)30(1) dispersion remained fluid at $\mathrm{pH} 8.0$ (Fig. 2b). We therefore extended this approach to prepare a range of core-shell nanoparticle dispersions (Table 1). It was found that inclusion of 1 wt. \% BDDA within the nanoparticle shells prevented pH-triggered swelling (Fig. 2a) and enabled good quality films to be obtained by casting for all of the C55(0)-x(1) ( $x=20$ to 30) and C19(0)-30(1) dispersions.

\section{Nanostructured ionomer film morphology}

The topography of the films was investigated using AFM. Phase images for C19(0)-30(1), C55(0)-30(1) and C55(0)-20(1) nanoparticle films in the non-neutralised (0n, top row) and neutralised (100n, bottom row) states are shown in Fig. 3. Whilst there was some distortion of the nanoparticles due to local strain, the C19(0)-30(1) (Fig. 3a and b) and C55(0)-30(1) (Fig. $3 \mathrm{c}$ and d) films showed nanostructured topographies that consisted of interconnected nanoparticles. Those nanoparticles appeared to be mostly spherical for the 100n films. Ionic crosslinking within the shells increased the ability of the nanoparticles to retain their spherical morphology. By contrast the C55-20(1) (Fig. 3e and f) film topographies were less well-defined (especially in the non-neutralised, 0n, state) and showed greater extents of coalescence of neighbouring nanoparticles. As will be shown below, the $T_{g}$ of the nanoparticle shell phase was lowest for C55(0)-20(1) (See Fig. 4f). It appears from the images shown in Fig. 3 that the extents of inter-nanoparticle coalescence increased with decreasing nanoparticle $T_{g}$, which is expected because of increased polymer segment mobility. When combined with the core-shell morphology established above the data support the depiction of the nanostructured film morphology shown in Scheme 1b.

\section{Nanostructured ionomer film mechanical properties}

DMA has been shown to be a very useful technique for studying conventional ${ }^{13}$ and nanostructured ${ }^{9}$ ionomer mechanical properties. DMA data for the present films are shown in figures 4 and 5 . The $T_{g}$ values obtained from these data are shown in Table S1. Considering first the data for the C19(0)-30(1) and C55-30(1) films two main $\tan \delta$ maxima can be seen from figures $4 \mathrm{a}$ and c. (Note that $\tan \delta=E^{\prime}$ / $E^{\prime}$, where $E^{\prime \prime}$ and $E^{\prime}$ are the loss and storage modulus values, respectively.) The tan $\delta$ maximum in the temperature range of -40 to $-45^{\circ} \mathrm{C}$ corresponds to the $T_{g}$ value for PBA residing in the core of the nanoparticles, i.e., $T_{g(c)}$. This 
range of temperatures is comparable to the reported $T_{g}$ value of $-49{ }^{\circ} \mathrm{C}$ for $\mathrm{PBA}^{10}$. The relative size of the $T_{g(c)}$ maxima was smallest for C19(0)-30(1) (Fig. 4a) which is expected because those nanoparticles contained the lowest core volume fraction (19 vol.\%). The higher temperature maximum present at $33-46{ }^{\circ} \mathrm{C}$ was dependent on the extent of neutralisation and corresponds to the $T_{g}$ from PBA-AN-MAA within the shells $\left(T_{g(s)}\right)$. This $T_{g}$ value is much higher than that for PBA because of contributions from AN and MAA. The $T_{g} \mathrm{~S}$ of PAN and PMAA are $105{ }^{\circ} \mathrm{C}^{36}$ and $228{ }^{\circ} \mathrm{C}^{10}$, respectively. The variable temperature $E$ ' and $E$ " data (Figures $4 \mathrm{~b}$ and $\mathrm{d}$ ) indicate that the two $\tan \delta$ maxima discussed above originated from temperature-triggered decreases of $E^{\prime}$ and increases of $E$ ”.

DMA data for C55(0)- $x(1)(x=20,23$ and 28) films are shown in Fig. 5. Similar low and high temperature $\tan \delta$ maxima were also present for the these films (Fig. 5a, c and e). The variable temperature $E^{\prime}$ and $E^{\prime \prime}$ data for these films (Figures $5 \mathrm{~b}, \mathrm{~d}$ and $\mathrm{f}$ ) showed similar trends to those apparent from Fig. $4 \mathrm{~b}$ and d. Considering all of these variable-temperature $E$ ' and $E$ " data it can be seen that a consequence of ionic crosslinking (either $50 \%$ or $100 \%$ neutralisation) was that the $E^{\prime}$ values increased relative to the non-neutralised films for temperatures greater than $\sim 50{ }^{\circ} \mathrm{C}$. Moreover, a higher temperature $\tan \delta$ shoulder was also evident at $\sim 100-110{ }^{\circ} \mathrm{C}$ for most of the neutralised films (e.g., Fig. 5e) and this $T_{g}$ is ascribed to domains containing ionic crosslinks $\left(T_{g(i)}\right)$ involving $\mathrm{K}^{+}$and / or $\mathrm{Zn}^{2+}$ with $-\mathrm{COO}^{-}$. It is proposed that the temperature-triggered structural transition that occurred for the latter was disruption of ionic crosslinks. Attractive electrostatic interactions of ion pairs within polymers are known to become less effective at elevated temperatures ${ }^{37}$. The tan $\delta$ peaks due to $T_{g(c)}, T_{g(s)}$ and $T_{g(i)}$ discussed above are highlighted in Fig. 5e.

The variation of the $T_{g(s)}$ values with the AN content $(x)$ for the C55(0)-x(1) films is shown in Fig. 6. (Data are also shown for the C19(0)-30(1) film.) Clearly, the $T_{g(s)}$ values increased with $x$. The $T_{g(s)}$ values also increased with neutralisation (see C19(0)-30(1) data); however, this trend was generally less pronounced. The increase of the $T_{g(s)}$ values with $x$ is expected because AN segments are known to increase the $T_{g}$ value for copolymers ${ }^{38}$ and contribute strong nitrile dipolar interactions between polymer chains ${ }^{39}$, which increase chain stiffness.

The present nanostructured films can be divided into two groups according to their $T_{g(s)}$ values compared to room temperature (horizontal line in Fig. 6). Accordingly, the C55(0)20(1) and C55(0)-23(1) films had relatively low $T_{g(s)}$ values. By contrast, the C55(0)-28(1), C55(0)-30(1) and C19(0)-30(1) films had relatively high $T_{g(s)}$ values. For comparison, the $T_{g(s)}$ 
values for the previously studied nanostructured films prepared using Bd-nanoparticles ${ }^{8}$ were less than $0{ }^{\circ} \mathrm{C}$ irrespective of the $\mathrm{AN}$ contents. Consequently, the present BA-based films enabled $T_{g(s)}$ values, which were close to room temperature, to be switched from being more glass-like to more rubber-like (and closer to Bd-based films) by judicious selection of $x$.

Next we investigated the effects of film composition on the tensile properties. Tensile stressstrain data for the nanostructured films are shown in Fig. 7. (The tensile parameter values appear in Table S1.) There were pronounced differences for the curves as either $x$ or the extent of neutralisation was varied. Considering first C19(0)-30(1) and C55(0)-30(1) (Fig. 7a and b) the data show a steep linear increase of stress with increasing strain (pure elastic behaviour) followed by an inelastic deformation region and, finally, strain hardening prior to failure. These features were also present for the other films (Fig. 7c - e)); however, their extents differed. An increase of the shell volume fraction $\left(\phi_{s}\right)$ from 0.45 (for C55(0)-30(1)) to 0.81 (for $\mathrm{C} 19(0)-30(1)$ ) increased the extent of the initial linear region and the final shear-atbreak $\left(\sigma_{b}\right)$. Interestingly, comparison of the data shown in Fig. 7a and b (and Table S1) reveals that an increase of the $\phi_{s}$ value by a factor of $\sim 2$ increased the $E$ values by a factor of $\sim 2$ with only a small decrease of the strain-at-break $\left(\varepsilon_{b}\right)$, and hence ductility. This result is consistent with a property tuning advantage reported earlier for lower modulus nanostructured ionomer films constructed from Bd-based core-shell nanoparticles where stiffness and ductility could be independently tuned ${ }^{24}$.

Turning next to the effect of AN content $(x)$ it can be clearly seen from comparison of the data in Fig. $7 \mathrm{a}-\mathrm{e}$ that the films with the highest $x$ values had the highest $E$ and $\sigma_{b}$ values (Table $\mathrm{S} 1$ ). The maximum $E$ value for this work was $85.5 \mathrm{MPa}$ which was measured for the fully neutralised C19(0)-30(1) film. The latter value is the highest modulus that has been reported for nanostructured ionomer films prepared by casting aqueous dispersions of coreshell nanoparticles. All of the films had $\varepsilon_{b}$ values of at least $200 \%$, which compares well with other ionomers $^{40}$. The non-neutralised C55(0)-20(1) film had the highest $\varepsilon_{b}$ value of $445 \%$.

Fig. 7f shows the variation of $E$ as a function of $x$ for the C55(0)-x(1) films. Data are also shown for the C19(0)-30(1) film. A major $E$ increase occurred when $x$ reached $28 \%$. The latter film (C55(0)-28(1)) had a $T_{g(s)}$ value of $\sim 40{ }^{\circ} \mathrm{C}$ (Table S1), which was well above the tensile stress-strain measurement temperature $\left(25{ }^{\circ} \mathrm{C}\right)$ and those films were relatively glasslike. The high AN contents within the shells provided associative crosslinking which 
restricted the mobility of the copolymer chains. By contrast, the C55(0)-20(1) and C55(0)23(1)) films (which had the lowest $x$ and $T_{g(s)}$ values) had the lowest $E$ values (Fig. 7f). These data show that the $x$ value had a major effect on the $E$ values for these films due to its control of the $T_{g(s)}$ values in a temperature region that was reasonably close to room temperature. Considering the $E$ value spread shown for each $x$ value in Fig. $7 \mathrm{f}$ it can be seen that the effect of neutralisation on $E$ was most pronounced for the films with the highest $x$ values, which in turn gave the highest $T_{g(s)}$ values (Fig. 6). Thus, the ionomer contribution to the film stiffness was enhanced when $T_{g(s)}$ was shifted to above room temperature. This is a new finding for this class of ionomer films.

\section{A simple model describing the stiffness and ductility of the nanostructured ionomer films}

The isostrain model was originally developed by Morris ${ }^{41}$ for biphasic gels and is tested here for the present BA-based nanostructured films. For this mechanical model we consider the nanostructured films to consist of two phases (See Scheme 1b). The continuous phase consists of interlinked, relatively hard, PBA-AN-MAA-BDDA shell copolymer. The dispersed phase consists of relatively soft PBA core polymer. According to the isostrain model the modulus should be the volume fraction-weighted average for each phase and both phases should experience the same strain. Accordingly,

$E=\phi_{c} E_{c}+\phi_{s} E_{s}$

$\varepsilon_{b}=\varepsilon_{b(c)}=\varepsilon_{b(s)}$

where $E_{c}$ and $E_{s}$ are the Young's modulus values for the core and shell phases, respectively. The parameters $\varepsilon_{b(c)}$ and $\varepsilon_{b(s)}$ are the strain-at-break values for the core and the shell phases, respectively. The $E$ values for the films were all greater than $1 \mathrm{MPa}$ in this work. Furthermore, PBA films are known to be very soft ${ }^{42}$ and the $E$ value measured here for $\mathrm{C} 100(0)$ was only $0.19 \mathrm{MPa}$ (Table S1). Consequently, we assume that $\phi_{c} E_{c} \ll<\phi_{s} E_{s}$ for all of the systems studied here which allows equation 2 to be rearranged to the following.

$E_{S} \sim \frac{E}{1-\phi_{c}}$

Values for $E_{s}$ were calculated using equation (4) are shown as a function of neutralisation in Fig. 8a and b. The $E_{s}$ values for the high $T_{g(s)}$ films (C19(0)-30(1), C55(0)-30(1) and C55(0)28(1)) are shown in Fig. 8a; whereas, data for the low $T_{g(s)}$ films (C55(0)-23(1) and C55(0)20(1)) are shown in Fig. 8b. The $E_{s}$ values for the C19(0)-30(1) and C55(0)-30(1) values 
were not significantly different. This result was expected because the shells had the same composition (30\% AN) and supports the use of the isostrain model.

Implicit within the use of equation 4 is the assumption that $E_{s}$ should increase with neutralisation because of the formation of ionic crosslinks. The data in Fig. 8a also show that the $E_{s}$ values for the films with the higher $T_{g(s)}$ values increased approximately linearly with neutralisation, which is expected based on rubber elasticity theory ${ }^{43}$. Comparison with the data shown in Fig. $8 \mathrm{~b}$ shows that the magnitude of the $E_{s}$ increase was least for the low $T_{g(s)}$ films. Nevertheless, the increase of $E_{s}$ with neutralisation for the latter films was stronger than that for the Bd-containing system $(\mathrm{C} 50 \mathrm{Bd})$ which has been included in this analysis from earlier work ${ }^{8}$. This low $T_{g}$ system had $\phi_{s}=0.5$ and similar MAA contents to the BAcontaining films studied here and the data confirm the importance of $T_{g}$ for the ionomerinduced modulus enhancement for this class nanostructured films.

It is commonly observed for conventional elastomers that the ductility decreases with increasing stiffness. This trend has also been observed for Bd-based nanostructured ionomer films ${ }^{24}$ and has its origin in the inverse relationship between the number-density of elastically effective chains and the mean molecular weight between crosslinks. According to equation 3 the $\varepsilon_{b}$ values for the films should be controlled by the ductility of the nanoparticle shells because that phase was the most brittle. The variation of $\varepsilon_{b}$ with neutralisation is shown in Fig. 6c. Comparison with the data shown in Fig. 8a and b shows that the films which had highest $\varepsilon_{b}$ values (C55(0)-20(1), C55(0)-23(1) and C50Bd) had the lowest $E_{s}$ values. By contrast, the films which had the lowest lowest $\varepsilon_{b}$ values (C19(0)-30(1), C55(0)-30(1) and C55(0)-28(1)) had the highest $E_{s}$ values. Consequently, film ductility increased when the stiffness decreased for these systems and was controlled by the ionic crosslinks formed in the shells. Based on the above, we conclude that the isostrain model was able to successfully describe the mechanical properties of the nanostructured ionomer films.

The above discussion (and equations (2) and (3)) assumed that the soft PBA-phase was dispersed within interlinked, relatively hard, PBA-AN-MAA-BDDA shell copolymer. The inverse morphology should also be considered whereby the relatively hard shell copolymer is dispersed with a relatively soft continuous PBA phase. This situation corresponds to the isostress model of Morris ${ }^{41}$ and the following equation would apply. 
$\frac{1}{E}=\frac{\phi_{c}}{E_{C}}+\frac{\phi_{s}}{E_{S}}$

As stated above it is reasonable to assume that $E_{c} \ll E_{s}$. Furthermore, a minimum $E_{s}$ value can be estimated from the $E$ value for C19(0)-30(1) because these core-shell particles contained $\sim 81$ vol.\% shell copolymer. The latter value for the non-neutralised system was of 23.1 MPa (Table S1, $\dagger$ ). That value was much greater than the $E_{c}$ value which was estimated as $\sim 0.19 \mathrm{MPa}$ (above). Considering the $\phi_{c}$ and $\phi_{s}$ values for the systems studied here ( 0.19 to 0.55 and 0.81 to 0.44 , respectively), then it follows that $\phi_{c} / E_{c} \gg \phi_{s} / E_{s}$. Hence, equation (5) becomes $E_{c} \simeq \phi_{c} E$. From the latter and the $E$ data (Table S1, $\dagger$ ) it follows that $E_{c}$ would increase with increasing $\phi_{c}$, neutralisation and $x$. Each of these relationships is physically implausible. Consequently, it can be concluded that the isostress model, equation (5) and the inverse morphology do not apply to the films considered above.

\section{CONCLUSIONS}

This study has investigated the structure and mechanical properties of nanostructured ionomer films comprised of BA-based core-shell nanoparticles. By replacing Bd with BA pronounced differences in the nanoparticle properties and film mechanical properties were demonstrated. A key difference was that inclusion of shell crosslinker (BDDA) was required to suppress pH-triggered shell swelling of the nanoparticles and enable ionomer film formation to occur. By varying the AN content within the shells it was possible to transform the stress-strain behaviour from that which was comparable to the earlier Bd-based films ${ }^{8}$ to a much higher modulus version. The DMA data showed that these changes were due primarily to the increase of the shell $T_{g}$. The maximum modulus value of $85.5 \mathrm{MPa}$ reported here was a factor of at least seven higher than those reported earlier for Bd-based nanostructured ionomer films ${ }^{8,9,24}$. The mechanical properties (i.e., $E$ and $\varepsilon_{B}$ ) of the BA-based films were controllable via three composition-based variables: \% neutralisation, AN content $(x)$ and $\phi_{s}$. More generally, we have also shown that the nature of the primary monomer used to construct nanostructured ionomer films based on core-shell nanoparticles provides a new parameter for tuning the mechanical properties. The mechanical properties of the films were successfully described using the isostrain model. The methods for synthesising the core-shell nanoparticles and casting the films used commonly available equipment (with no need for pressurised reactors ${ }^{8}$ ), were water-based and are versatile. Consequently, there should be scope for preparing nanostructured films with enhanced performance that are able to be cast from aqueous dispersions using new acrylate-based core-shell nanoparticles in future. 


\section{Acknowledgements}

BRS is grateful to Synthomer Ltd and The Malaysian Government Agency (MARA) for funding this work.

\section{References}

1. M. B. Gawande, A. Goswami, T. Asefa, H. Guo, A. V. Biradar, D.-L. Peng, R. Zboril, and R. S. Varma. Chem. Soc. Rev. 2015, 44, 7540-7590.

2. R. A. Ramli, W. A. Laftah, and S. Hashim. RSC Advances 2013, 3, 15543-15565.

3. N. Sahiner, A. M. Alb, R. Graves, T. Mandal, G. L. McPherson, W. F. Reed, and V. T. John. Polymer 2007, 48, 704-711.

4. I. Berndt, J. S. Pedersen, and W. Richtering. J. Amer. Chem. Soc. 2005, 127, 9372-9373.

5. H. K. Feng, Y. Zhao, M. Pelletier, Y. Dan, and Y. Zhao. Polymer 2009, 50, 3470-3477.

6. K. S. Soppimath, D. W. Tan, and Y. Y. Yang. Adv. Mater. 2005, 17, 318-323.

7. F. Gambinossi, and J. K. Ferri. Coll. Surf. A. 2015, 464, 143-153.

8. S. Tungchaiwattana, M. S. Musa, J. Yan, P. Lovell, P. Shaw, and B. R. Saunders. Soft Matter $2014,10,4725-4734$.

9. O. Pinprayoon, R. Groves, P. A. Lovell, S. Tungchaiwattana, and B. R. Saunders. Soft Matter 2011, 7, 247-257.

10. J. Brandrup, E. H. Immergut, E. A. Grulke, A. Abe, and D. R. Bloch (1999) Polymer handbook, Vol. 89, Wiley New York.

11. A. Eisenberg. Macromolecules 1970, 3, 147-154.

12. A. Eisenberg, B. Hird, and R. Moore. Macromolecules 1990, 23, 4098-4107.

13. A. Eisenberg, and J.-S. Kim (1998) Introduction to ionomers, Wiley New York.

14. I. Capek. Adv. Coll. Interf. Sci. 2004, 112, 1-29.

15. A. Arora, E. Daniels, and M. El-Aasser. J. Appl. Polym. Sci. 1995, 58, 301-311.

16. H.-B. Kim, and M. A. Winnik. Macromolecules 1995, 28, 2033-2041.

17. R. S. Gurney, A. Morse, E. Siband, D. Dupin, S. P. Armes, and J. L. Keddie. J. Coll. Interf. Sci. 2015, 448, 8-16.

18. R. K. Bose, N. Hohlbein, S. J. Garcia, A. M. Schmidt, and S. van der Zwaag. Phys. Chem. Chem. Phys. 2015, 17, 1697-1704.

19. M. E. Seitz, C. D. Chan, K. L. Opper, T. W. Baughman, K. B. Wagener, and K. I. Winey. J. Amer. Chem. Soc. 2010, 132, 8165-8174.

20. Y. Nakayama, T. Inaba, Y. Toda, R. Tanaka, Z. Cai, T. Shiono, H. Shirahama, and C. Tsutsumi. J. Polym. Sci. (A), Polym. Chem. 2013, 51, 4423-4428.

21. L. Cui, C. Troeltzsch, P. J. Yoon, and D. R. Paul. Macromolecules 2009, 42, 2599-2608.

22. S. J. Kalista, J. R. Pflug, and R. J. Varley. Polym. Chem. 2013, 4, 4910-4926.

23. O. Pinprayoon, A. Saiani, R. Groves, and B. R. Saunders. J. Coll. Interf. Sci. 2009, 336, 73-81.

24. S. Tungchaiwattana, R. Groves, P. A. Lovell, O. Pinprayoon, and B. R. Saunders. J. Mater. Chem. 2012, 22, 5840-5847.

25. N. Gupta, R. Rai, A. Sikder, S. Nandi, A. Tanwar, R. Khatokar, S. D. Pask, and S. Mitra. RSC Advances 2016, 6, 37933-37937.

26. R. Browning, H. J. Sue, R. Minkwitz, and P. Charoensirisomboon. Polym. Eng. Sci. 2011, 51, 2282-2294.

27. H. Kim, H. Keskkula, and D. Paul. Polymer 1991, 32, 1447-1455.

28. B. G. Min, T. W. Son, W. H. Jo, and S. G. Choi. J. Appl. Polym. Sci. 1992, 46, 1793-1798.

29. O. Ruzimuradov, G. Rajan, and J. Mark. (2006) Thermal Properties of Nanostructured Poly (acrylonitrile)-Silica Materials, In Macromol. Symp., pp 322-324, Wiley Online Library.

30. Y. Yang, E. S. Daniels, and A. Klein. J. Appl. Polym. Sci. 2015, 132.

31. L. u. Černáková, V. Chrástová, and P. Volfová. Journal of Macromolecular Science, Part A 
2005, 42, 427-439.

32. X. Wang, and H. Li. J. Appl. Polym. Sci. 2000, 77, 24-29.

33. W. Ye, M. F. Leung, J. Xin, T. L. Kwong, D. K. L. Lee, and P. Li. Polymer 2005, 46, 10538-10543.

34. S. Tungchaiwattana, R. Groves, P. A. Lovell, O. Pinprayoon, and B. R. Saunders. J. Mater. Chem. 2012, 22, 5840.

35. R. A. Reichle, K. G. McCurdy, and L. G. Hepler. Can. J. Chem. 1975, 53, 3841-3845.

36. B. Dufour, C. Tang, K. Koynov, Y. Zhang, T. Pakula, and K. Matyjaszewski. Macromolecules 2008, 41, 2451.

37. C. Xu, L. Cao, B. Lin, X. Liang, and Y. Chen. ACS Appl. Mater. Interf. 2016, 8, 17728-17737.

38. K. I. Suresh, B. S. Sitaramam, and K. V. Raju. Macromol. Mater. Eng. 2003, 288, 980-988.

39. T. Bai, P. Zhang, Y. Han, Y. Liu, W. Liu, X. Zhao, and W. Lu. Soft Matter 2011, 7, 2825-2831.

40. N. Hohlbein, A. Shaaban, A. Bras, W. Pyckhout-Hintzen, and A. Schmidt. Phys. Chem. Chem. Phys. 2015, 17, 21005-21017.

41. E. R. Morris. Carbohyd. Polym. 1992, 17, 65-70.

42. C. Former, J. Castro, C. M. Fellows, R. I. Tanner, and R. G. Gilbert. J. Polym. Sci. (A), Polym. Chem. 2002, 40, 3335-3349.

43. L. R. G. Treloar (2005) The physics of rubber elasticity, 3rd ed., Clarendon, Oxford. 
Figures and Tables

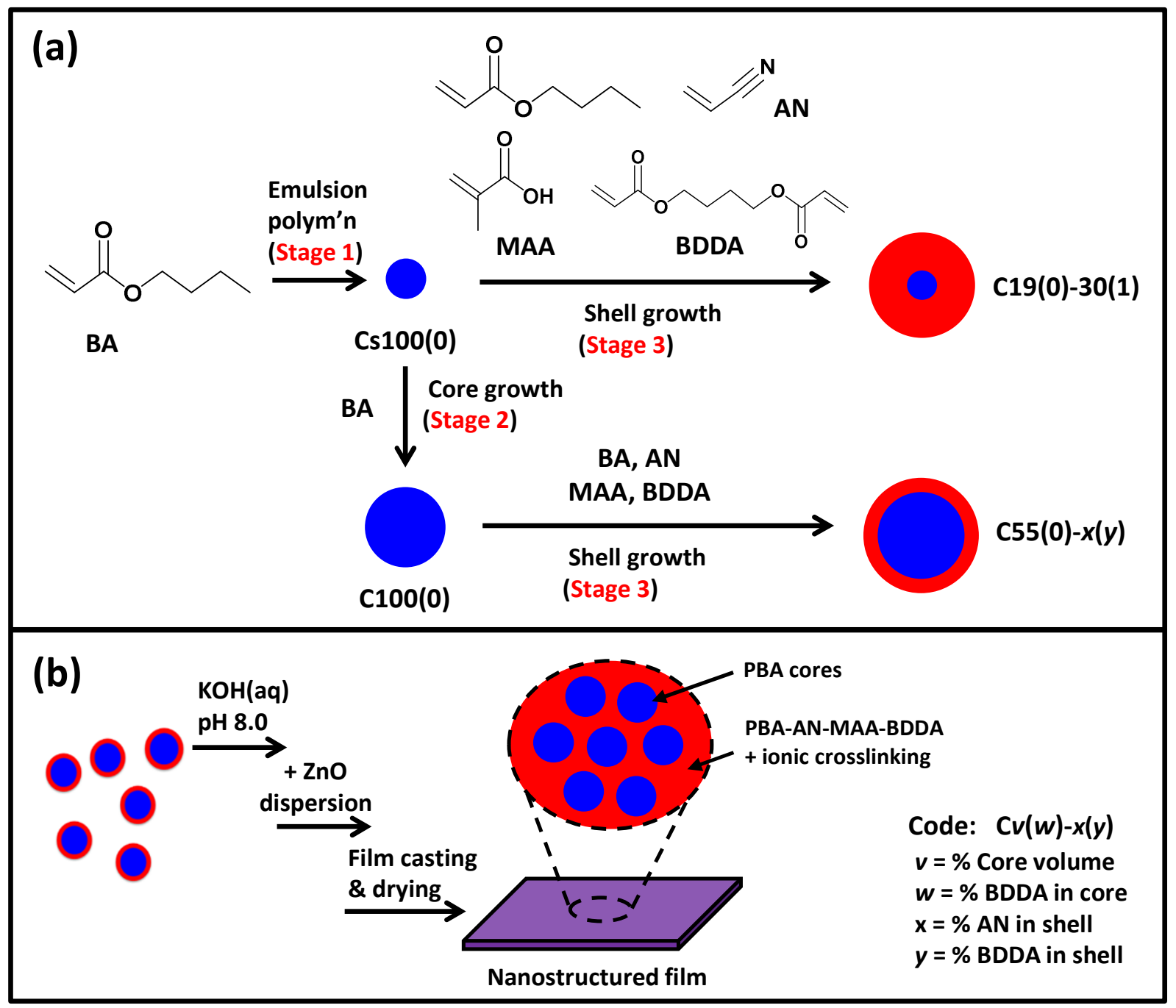

Scheme 1 (a) Depicts core-shell nanoparticle synthesis by seeded emulsion polymerisation. The method diverged after Stage 1. In the lower branch the PBA seed (Cs100(0)) was grown (Stage 2) to give larger PBA core $(\mathrm{C} 100(0))$ nanoparticles which were then used to prepare high core volume fraction C55(0)-x(y) nanoparticles. In the upper branch the Cs100(0) seed was used directly to prepare low core volume fraction C19(0)-30(1) nanoparticles. (b) Depicts the formation of nanostructured ionomer films after dispersion $\mathrm{pH}$ adjustment and addition of $\mathrm{ZnO}$ followed by casting. The code used for the nanoparticles and films is shown in (b). 

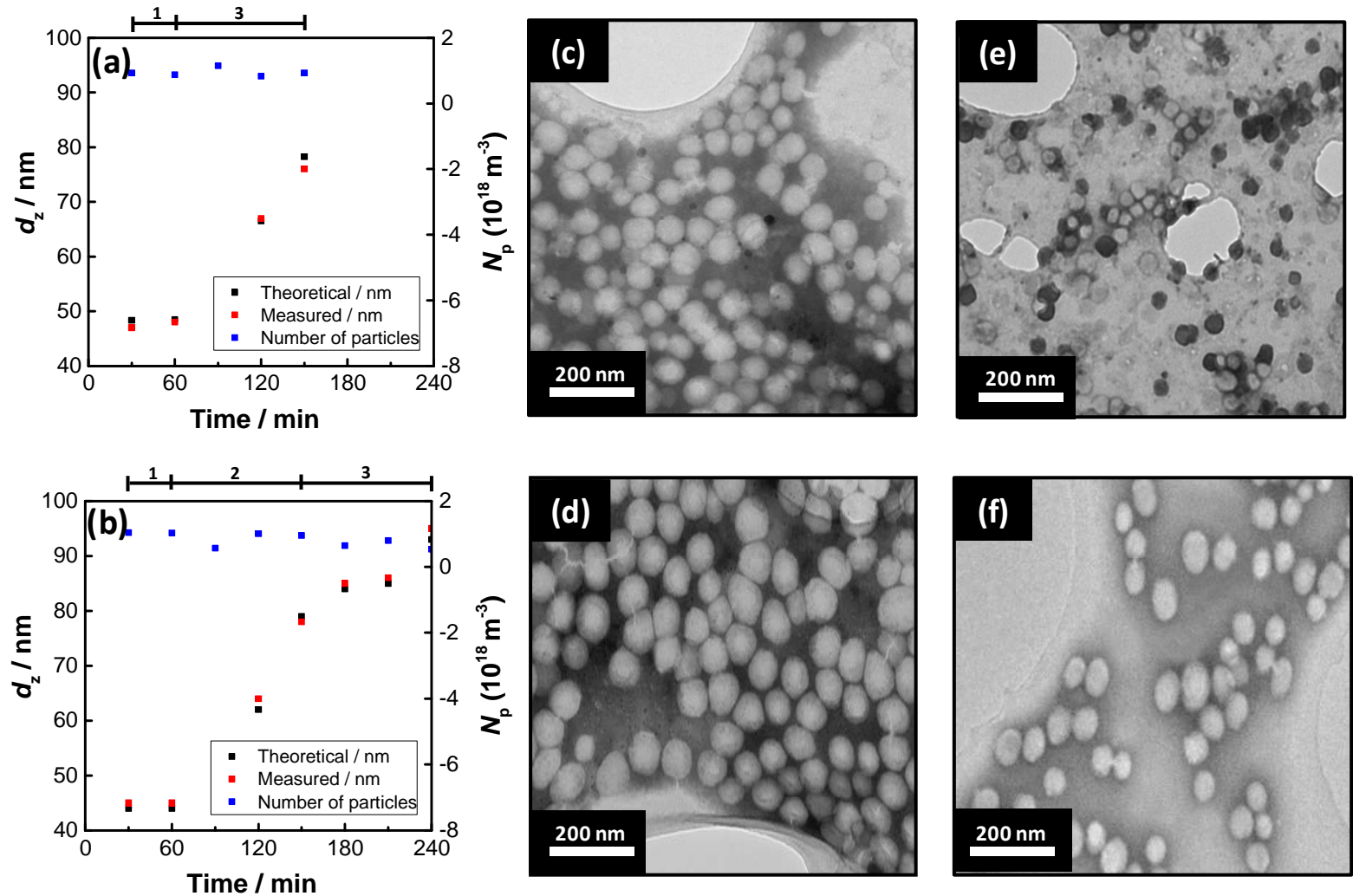

Fig. 1. (a) and (b) show measured particle diameters (red squares) during growth for C19(0)30(1) and C55(0)-30(1), respectively. The theoretical diameter values (black squares) and the number-density of nanoparticles (blue squares) are also shown. The numbers at the top of the graphs show the different stages of growth (Scheme 1a). TEM images are shown for (c) C19(0)-30(1) and (d) C55(0)-30(1) which were prepared using (e) seed Cs100(0) and (f) core C100(0) nanoparticles, respectively. 


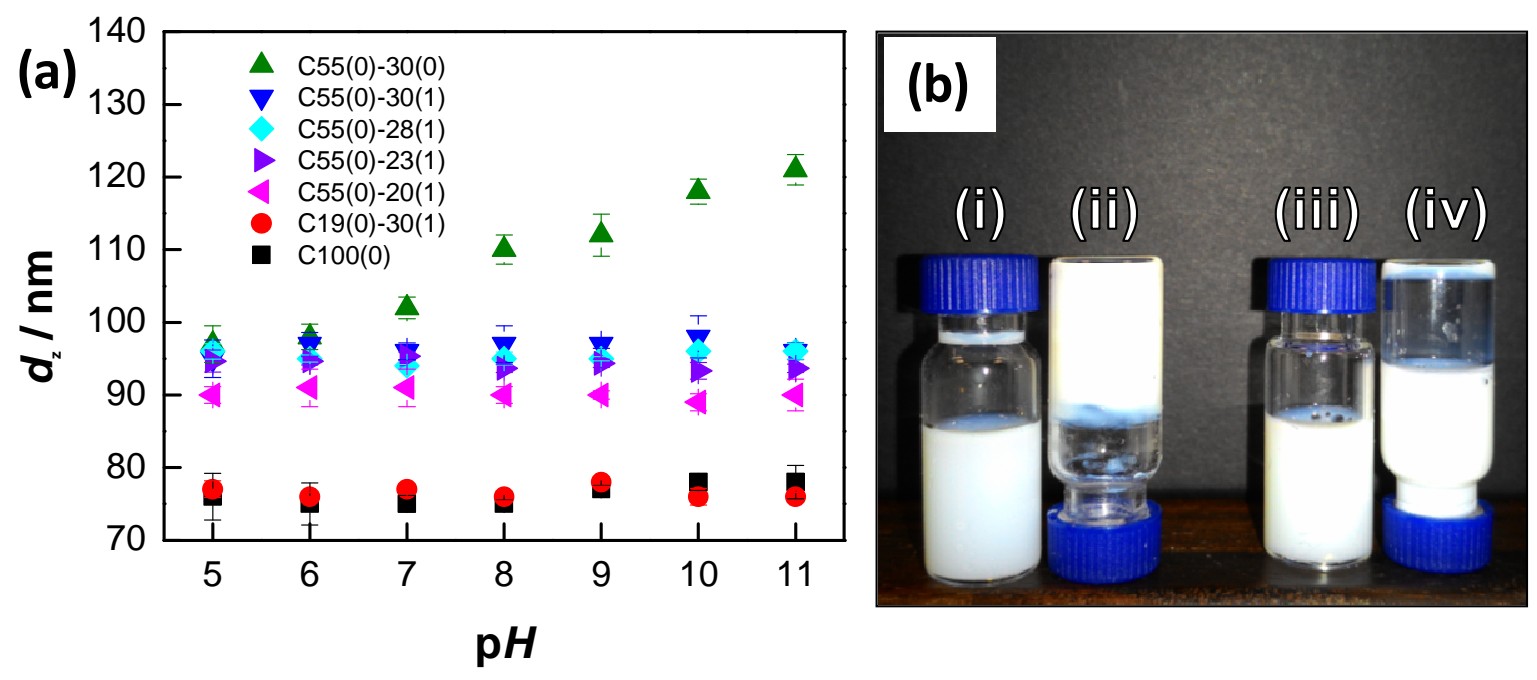

Fig. 2. (a) Variable pH DLS data for various nanoparticle dispersions. (b) Photographs of dispersions of C55(0)-30(0) ((i) and (ii)) and C55(0)-30(1) ((iii) and (iv)). The $\mathrm{pH}$ of samples (i) and (iii) was 3.0. The $\mathrm{pH}$ of samples (ii) and (iv) was 8.0. The concentration was $30 \mathrm{wt} \%$ 

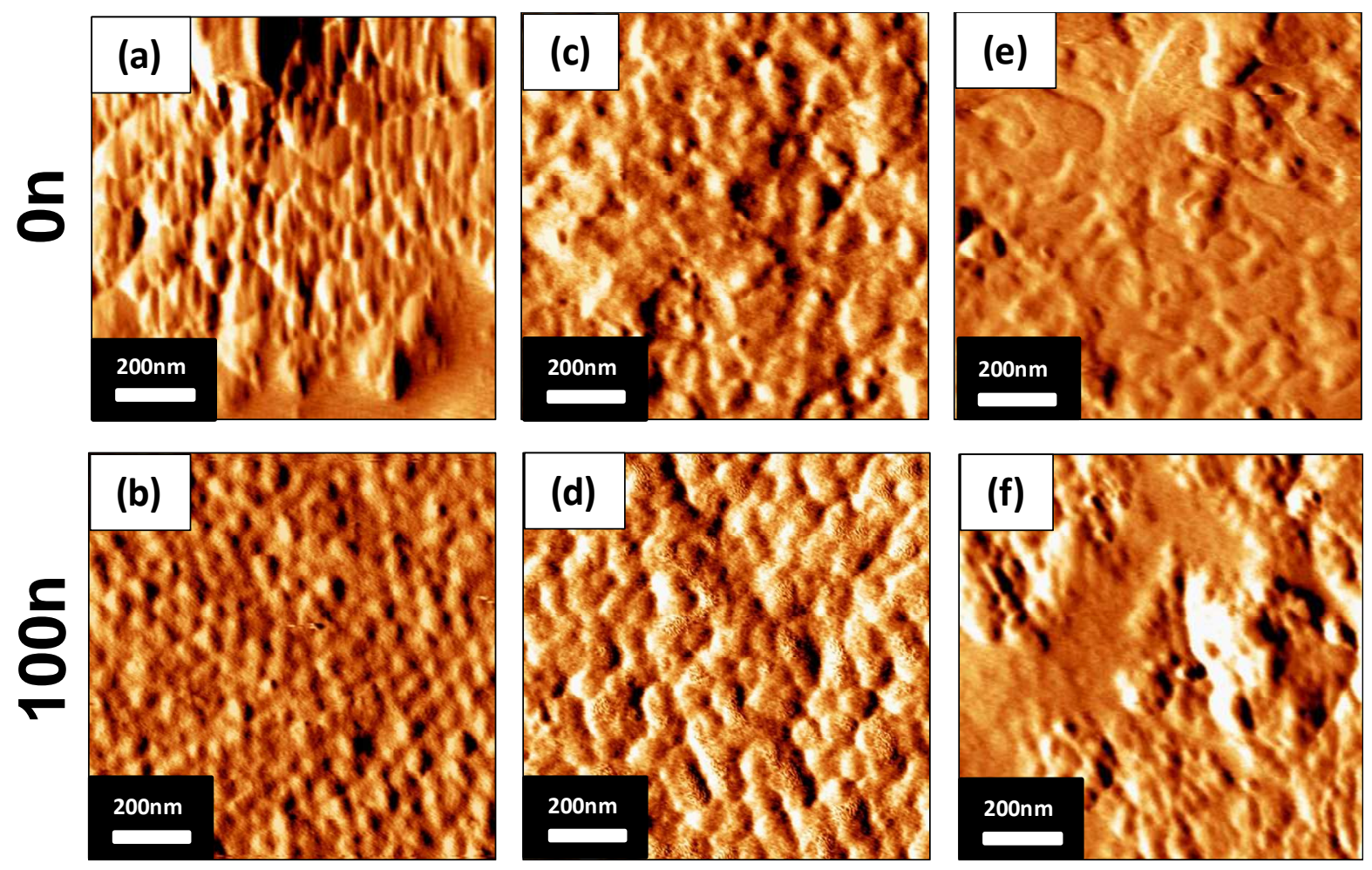

Fig. 3. AFM phase images for selected non-neutralised (0n, top row) and neutralised (100n, bottom row) nanostructured films. The films were C19(0)-30(1) (a and b), C55(0)-30(1) (c and d) and C55(0)-20(1) (e and f). The films were measured at $25{ }^{\circ} \mathrm{C}$. 

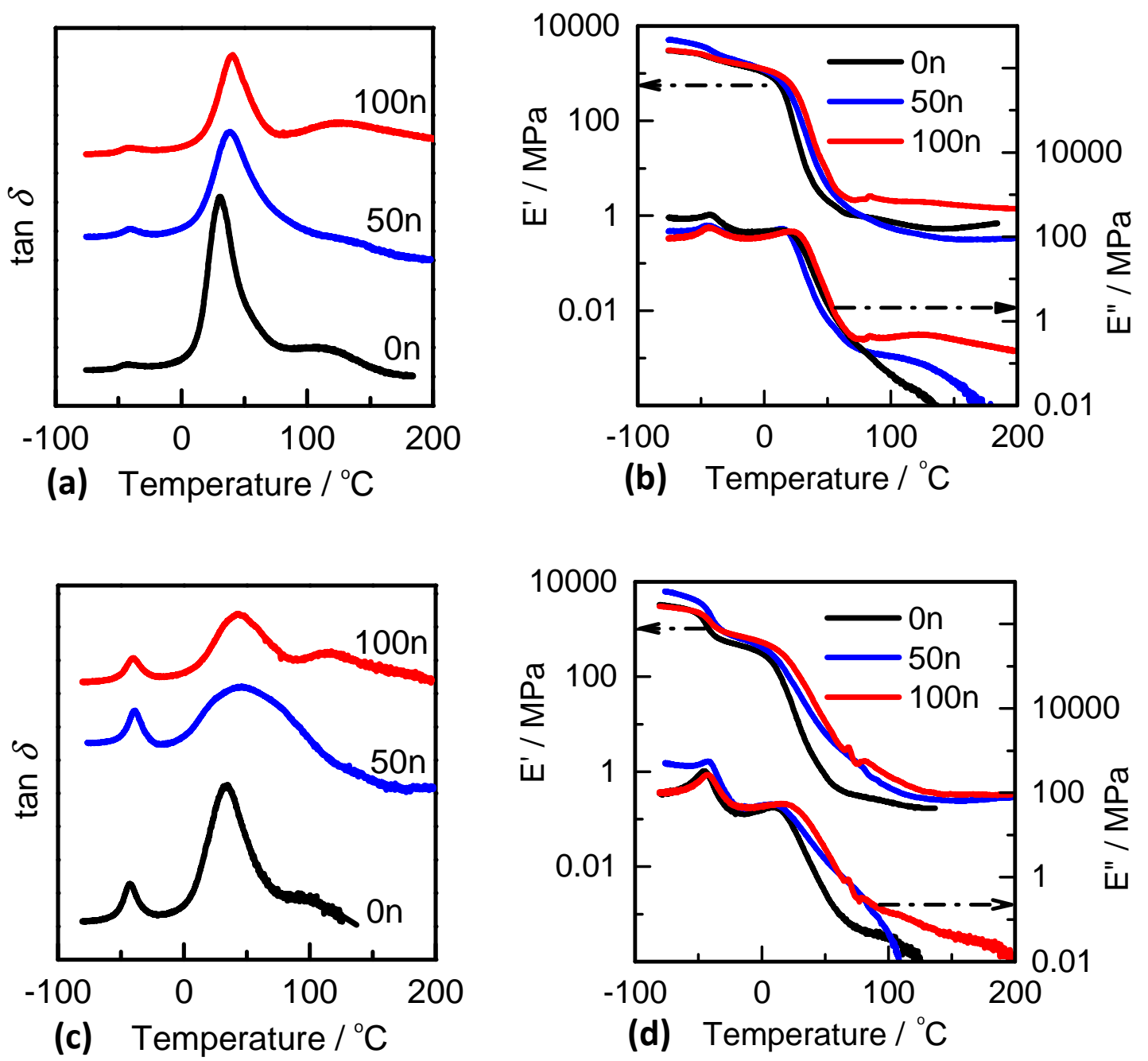

Fig. 4. Variation of $\tan \delta\left(=E ” / E\right.$, where $E^{\prime \prime}$ and $E^{\prime}$ are the loss and storage modulus, respectively) as well as $E^{\prime}$ and $E^{\prime \prime}$ with temperature for C19(0)-30(1) ((a) and (b)) and C55(0)-30(1) ((c) and (d)) films. 


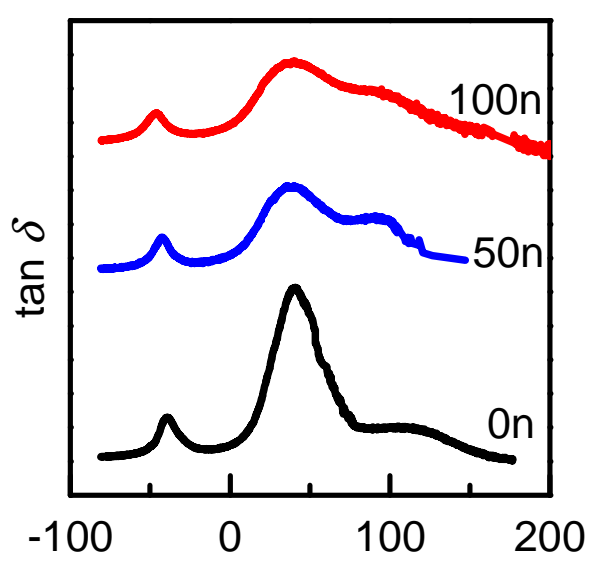

(a) Temperature $/{ }^{\circ} \mathrm{C}$

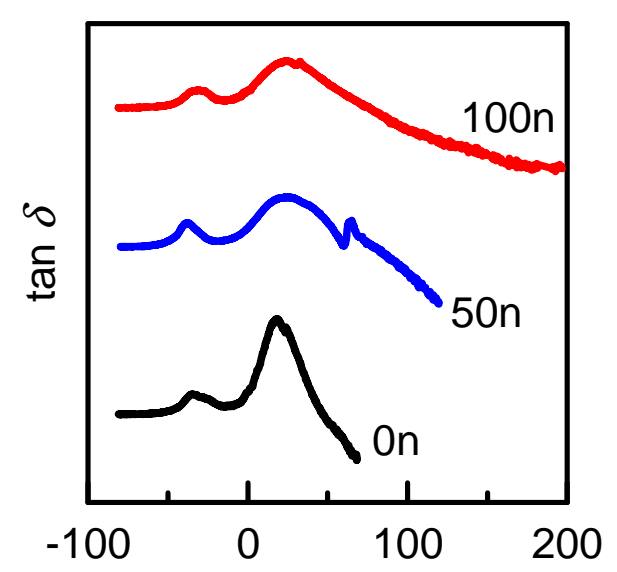

(c) Temperature $/{ }^{\circ} \mathrm{C}$

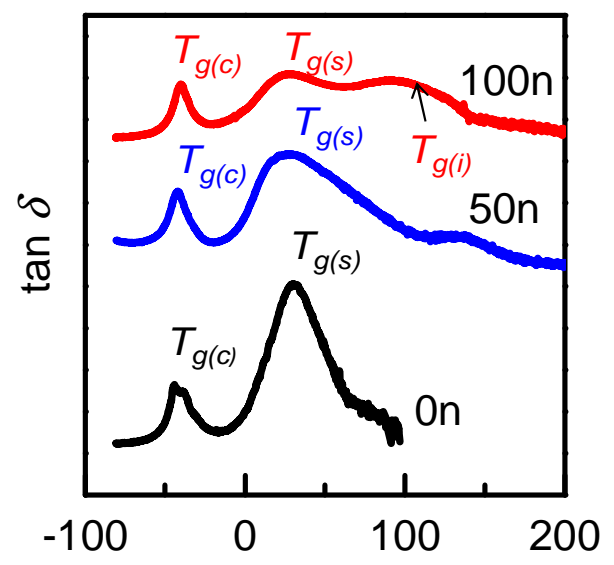

(e) Temperature $/{ }^{\circ} \mathrm{C}$

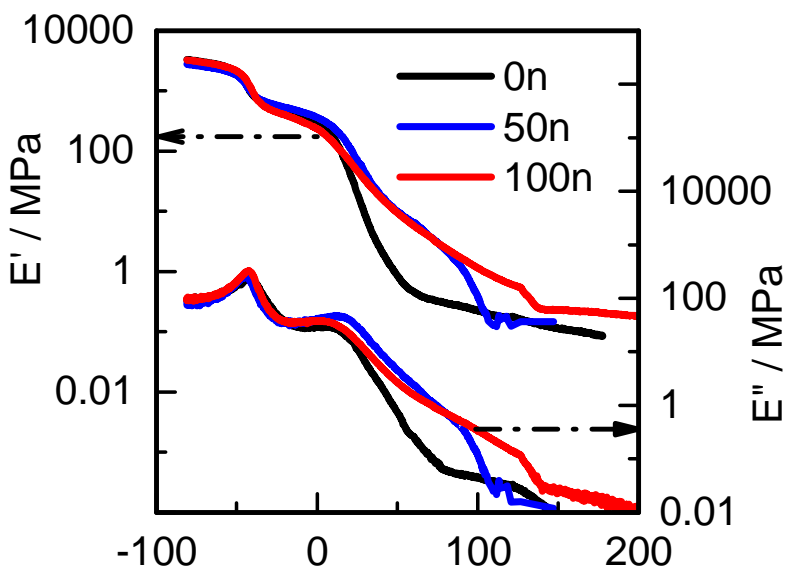

(b) Temperature $/{ }^{\circ} \mathrm{C}$

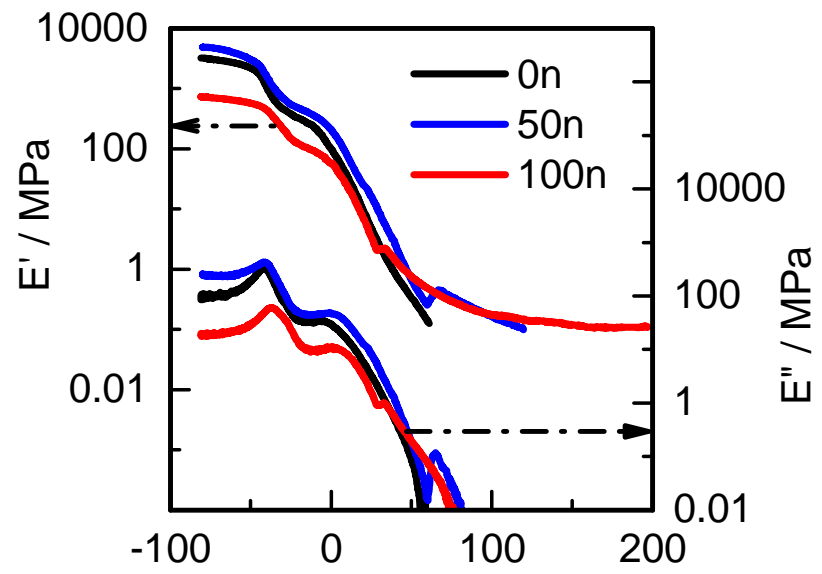

(d) Temperature $/{ }^{\circ} \mathrm{C}$

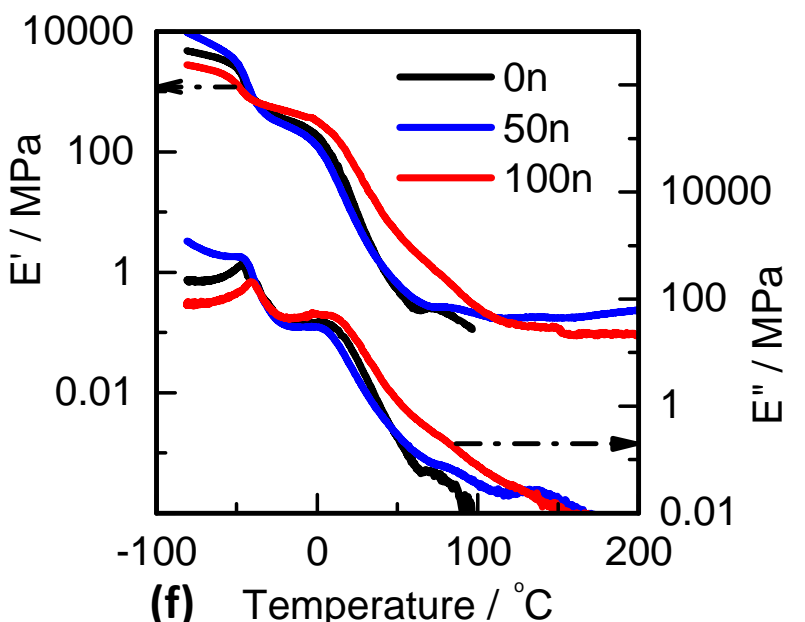

(f) Temperature $/{ }^{\circ} \mathrm{C}$

Fig. 5. Variation of $\tan \delta, E^{\prime}$ and $E^{\prime \prime}$ with temperature for C55(0)-28(1) ((a) and (b)), C55(0)-23(1) ((c) and (d)) and C55(0)-20(1) ((e) and (f)) ionomer films. The tan $\delta$ maxima corresponding to $T_{g(c)}, T_{g(s)}$ and $T_{g(i)}$ are shown in (e). The small, sharp signal at $\sim 60{ }^{\circ} \mathrm{C}$ in (c) for the $50 \mathrm{n}$ film is an artefact. 


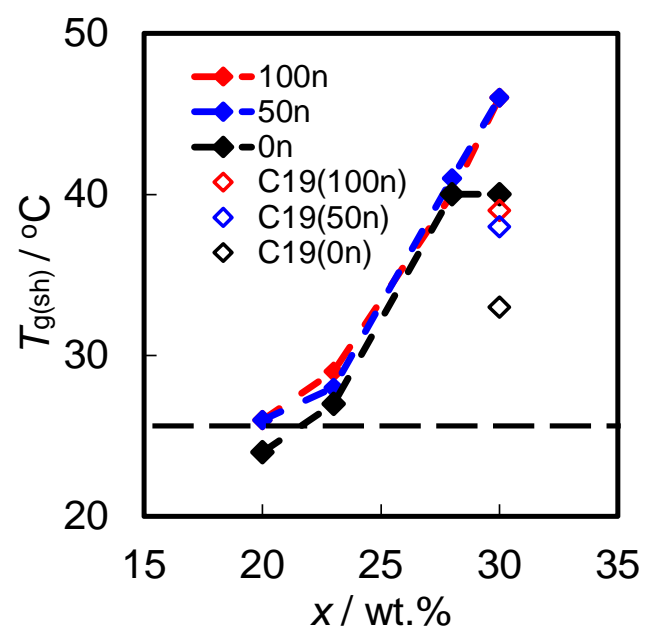

Fig. 6. Variation of $T_{g(s)}$ with $x$ for the C55(0)-x(1) films. Data for C19(0)-30(1) are also shown. $x$ is the nominal AN content in the shells of the core-shell nanoparticles. 


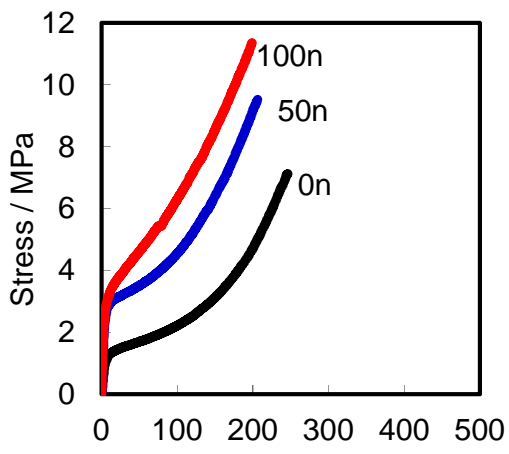

(a) Strain $/ \%$

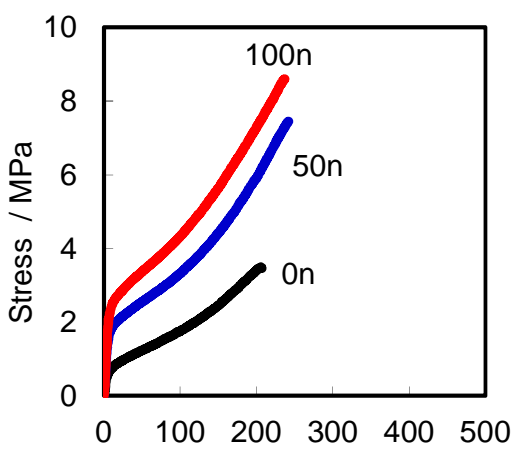

(b) Strain $/ \%$

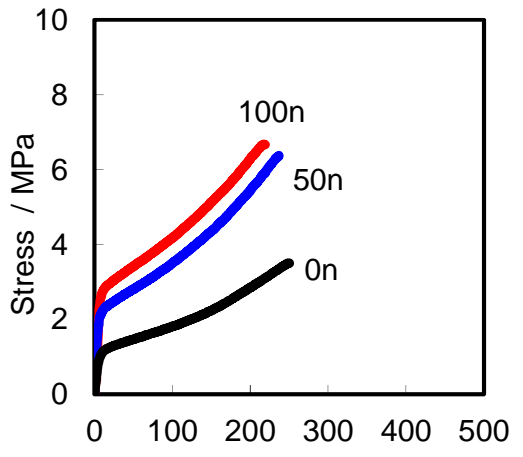

(c) $\quad$ Strain $/ \%$

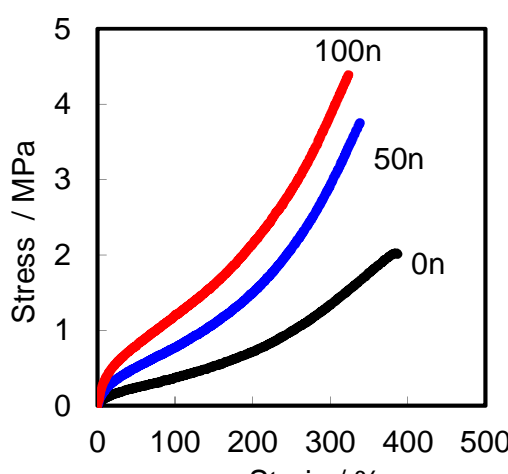

(d) Strain $/ \%$

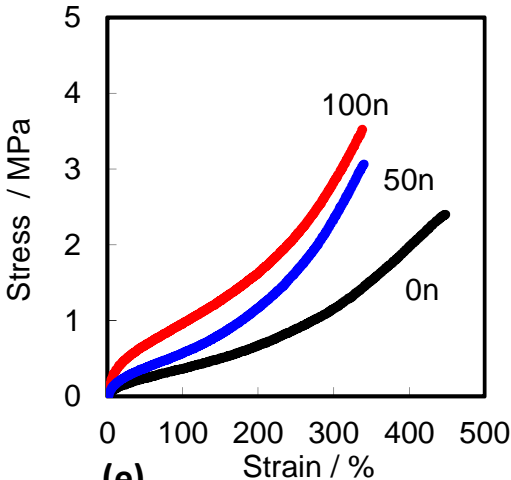

(e)

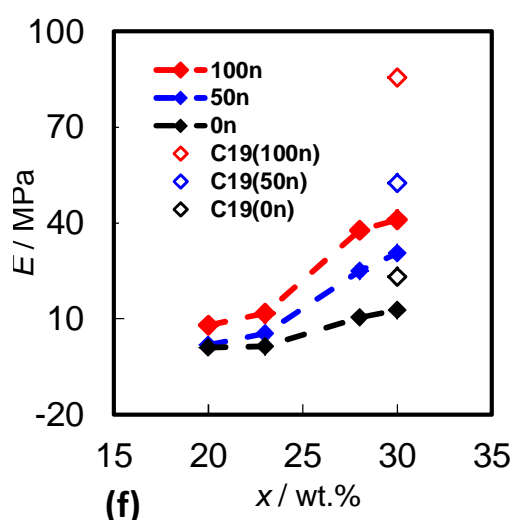

Fig. 7. Tensile stress vs. strain data for (a) C19(0)-30(1), (b) C55(0)-30(1), (c) C55(0)-28(1) (d) C55(0)-23(1) and (e) C55(0)-20(1) films. (f) shows the variation of $E$ with $x$ for the C55(0)- $x$ (1) films. Data for C19(0)-30(1) are also shown. 

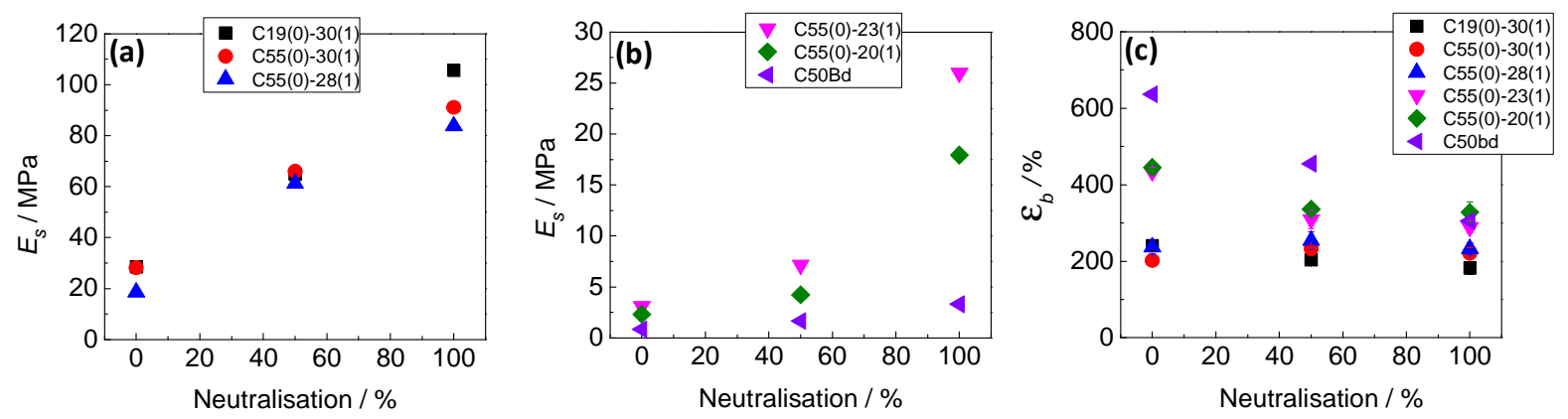

Fig. 8. (a) and (b) show the variations of the calculated shell modulus values from equation 4 with \% neutralisation for the films with high shell $T_{g(s)}$ values (C19(0)-30(1), C55(0)-30(1), and C55(0)-28(1)) and low $T_{g(s)}$ values (C55(0)-23(1), C55(0)-20(1), and C50Bd), respectively. (c) shows the variation of the strain-at-break for all of the films with $\%$ neutralisation. The data for the Bd-based film (C50Bd) shown in (b) and (c) were taken from an earlier study (Ref. 8). 
Table 1 Compositions and properties of the nanoparticles prepared for this study.

\begin{tabular}{|c|c|c|c|c|c|c|c|}
\hline Code & $\phi_{c(n o m)}{ }^{a}$ & $A N^{b} / w t \%$ & $d_{T E M}{ }^{c} / \mathrm{nm}$ & $d_{z}^{d} / \mathrm{nm}$ & $\delta_{D L S}{ }^{e} / \mathrm{nm}$ & $\mathrm{pK}_{a}^{f}$ & $M A A^{g} / w t^{\circ}$ \\
\hline Cs100(0) & 1.00 & - & $43(15)$ & 45 & - & - & - \\
\hline C100(0) & 1.00 & - & $80(28)$ & 79 & - & - & - \\
\hline C19(0)-30(1) & 0.19 & 30 & $63(16)$ & 76 & 15.5 & 7.4 & $3.8(4.0)$ \\
\hline C55(0)-30(0) & 0.55 & 30 & $93(20)$ & 97 & 9.0 & 7.0 & $2.9(2.3)$ \\
\hline C55(0)-30(1) & 0.55 & 30 & $91(15)$ & 95 & 8.0 & 6.8 & $2.1(2.3)$ \\
\hline C55(0)-28(1) & 0.55 & 28 & $84(14)$ & 96 & 8.5 & 6.7 & $2.6(2.3)$ \\
\hline C55(0)-23(1) & 0.55 & 23 & $81(24)$ & 93 & 7.0 & 6.9 & $2.3(2.3)$ \\
\hline C55(0)-20(1) & 0.55 & 20 & $83(20)$ & 90 & 6.0 & 7.0 & $2.5(2.3)$ \\
\hline
\end{tabular}

${ }^{a}$ Nominal volume fractions of core present based on $100 \%$ conversion. ${ }^{b}$ Nominal AN concentration in shell assuming $100 \%$ conversion. ${ }^{c}$ Number-average diameter measured by TEM (The numbers in brackets are the coefficient of variation). ${ }^{d}$ Values determined from DLS. ${ }^{e}$ Shell thicknesses calculated from DLS data using $\delta=\left(d_{z(c s)}-d_{z(c)}\right) / 2$ where the $d_{z}$ values are for the core-shell and core nanoparticles, respectively. ${ }^{f}$ Apparent $\mathrm{p} K_{\mathrm{a}}$ values determined from titration data. ${ }^{g}$ Overall concentration of MAA measured by titration. The numbers in brackets are the nominal values. 